\title{
PERCEPTIONS OF STIGMA AND DISCRIMINATION IN HEALTH CARE SETTINGS TOWARDS SUB-SAHARAN AFRICAN MIGRANT WOMEN LIVING WITH HIV/AIDS IN BELGIUM: A QUALITATIVE STUDY
}

\section{AGNES EBOTABE ARREY*1, JOHAN BILSEN*, PATRICK LACOR† AND REGINALD DESCHEPPER*}

* Mental Health and Wellbeing Research Group, Department of Public Health, Vrije Universiteit Brussel, Brussels, Belgium and $\dagger$ Department of Internal Medicine and Infectious Diseases-AIDS Reference Centre, Universitair Ziekenhuis Brussel, Brussels, Belgium

\begin{abstract}
Summary. Stigma and discrimination within health care settings remain a public health challenge across diverse cultural environments and may have deleterious effects on mental and physical health. This study explores the causes, forms and consequences of HIV-related stigma and discrimination among migrant sub-Saharan African women living with HIV in Belgium. A qualitative study was conducted with 44 HIV-positive sub-Saharan African migrant women between April 2013 and December 2014 in health care settings in Belgium. Data were analysed using thematic content analysis. Twenty-five of the women reported overt stigma and discrimination and fifteen reported witnessing behaviours that they perceived to be stigmatizing and discriminatory in health care settings. The themes that emerged as to the causes of stigma and discrimination were: public perceptions of migrants and HIV, fear of contamination and institutional policies on HIV management. Reported forms of stigma and discrimination included: delayed or denied care, excessive precautions, blame and humiliation. The consequences of stigma and discrimination were: emotional stress, inconsistent health-careseeking behaviour and non-disclosure to non-HIV treating personnel. Stigma and discrimination in health care settings towards people with HIV, and more specifically towards HIV-positive sub-Saharan African migrant women, impedes sustainable preventive measures. Specialized education and training programmes for non-HIV health care providers require in-depth investigation.
\end{abstract}

${ }^{1}$ Corresponding author. Email: aarrey@vub.ac.be 


\section{Introduction}

The persistence of stigma and discrimination is irrefutable, more than 30 years into the HIV epidemic (Grossman \& Stangl, 2013; Sidibe \& Goosby, 2013). Stigma is pervasive and profoundly disrupts individual as well as community health and well-being (Heijnders \& Van Der Meij, 2006; Kipp et al., 2011) and can be a determinant factor in health inequalities (Hatzenbuehler et al., 2013). Erving Goffman defined stigma as '... the phenomenon whereby an individual with an attribute which is deeply discredited by his or her society is rejected as a result of the attribute ...' (Goffman, 1963). Recently, research on stigma has focused on social power (Parker \& Aggleton, 2003) and the results of stigma, namely prejudice, shame, isolation, rejection and discrimination directed at people believed to have an illness or trait (Link \& Phelan, 2001). Sickness is bad enough, but there are some illnesses that lead to stigma and, eventually, discrimination - a direct act of unfair treatment. People have a tendency to see the person and not the disease as the problem (Thomas et al., 2008; Taylor, 2013), which may cause social and health inequities as well as structural violence (Parker, 2012).

Stigma affects the lives of people living with diseases such as leprosy (Adhikari et al., 2014), tuberculosis (Juniarti \& Evans, 2011), diabetes (Browne et al., 2013), mental illness (Beldie et al., 2012), HIV and, more recently, Ebola (Davtyan et al., 2014) and plays a significant role in these diseases. Some diseases are more stigmatizing than others and may be socially unacceptable. Being identified with one of these diseases causes fear and concern and may discourage people from seeking early treatment and care (Alemu et al., 2013), adhering to treatment or maintaining social networks. HIV stigma exists in every culture and setting and presents a public health challenge, and the degree of stigma differs from one disease to another and from one cultural setting to another (Shefer et al., 2013). HIV is considered the most stigmatized chronic disease in modern times across family, community and health care settings and in most cases individuals are left to shoulder the stigma and prejudices emanating from the public (Sartorius, 2009). People living with HIV bear the burden of keeping their illness. Fear of stigma is the main reason for non-disclosure of HIV-positive status to non-HIV health care providers, though HIV infection and AIDS are preventable illnesses (Bertozzi et al., 2006; DeMarco et al., 2009; De Cock et al., 2011; Conn, 2013).

Discrimination involves being treated differently or worse as a result of a particular characteristic. Discrimination against people living with HIV and AIDS still persists more than three decades into the HIV pandemic (Skinner \& Mfecane, 2004; Simbayi et al., 2007; Marsicano et al., 2014). Basic misinformation about HIV, how it is transmitted, and what it means to live with it is at the root of much of this discrimination and remains a justification for exclusions from both private and public sector employment opportunities and other areas of civic life. People have still to understand that HIV does not categorically prevent anyone from doing a job, childbearing (Saleem et al., 2015) or living a quality life (Parker \& Aggleton, 2003). Discrimination, or the fear of discrimination, has interfered, and is interfering, greatly with the ability of the public health officials to control this epidemic. There are examples around the world of discriminatory practices, including children being denied the opportunity to attend school because they are infected or affected (Surkan et al., 2010), and persons losing their jobs, losing their homes and even being denied medical services. It is evident in the literature that discrimination is closely linked with confidentiality and 
stigmatization (DeMarco et al., 2009; Nyblade et al., 2011; Canadian HIV/AIDS Legal Network, 2014).

Stigma and discrimination within health care settings remain a public health challenge across diverse cultural settings (Link \& Phelan, 2006; Lin et al., 2012). Vulnerable groups like homosexuals (Okall et al., 2014), drug users (Rance \& Treloar, 2014) and migrants (Seedat et al., 2014), especially from resource-poor countries with high HIV prevalence, experience discrimination as a result of stigma and negative attitudes of health care professionals (Barrett \& Mulugeta, 2010; Marsicano et al., 2014). The power of stigma and discrimination in health care settings may have deleterious effects on the mental and physical health of people, including sub-Saharan Africa (SSA) migrants, living with HIV who, along with men having sex with men (MSM), bear the brunt of HIV. Women all over the world represent a special group of people living with HIV because of their large number and their unique experiences as women, mothers and care-givers with the disease (Hackl et al., 1997; Kralik et al., 2001; Liamputtong, 2013). In the European Union, migrant women from resource-limited countries account for a large proportion of women with HIV (Barrett \& Mulugeta, 2010) and face a variety of forms of stigma and discrimination (Fakoya et al., 2008; ECDC, 2012).

Migrants living and ageing with HIV is a growing feature of the HIV/AIDS in Europe, and Belgium in particular. In many European countries, legal and political environments do not maximize the health and productivity of African migrants, who are disproportionately stigmatized and discriminated against for HIV transmission and exposure (Chalmers, 2002). Studies have shown that most migrants may have acquired HIV in their country of origin, and a small proportion may have been infected while they resided in the EU. Previous studies have shown that migrants perceive stigma, and consequently discrimination, not only among the community but also within health care settings (Lauderdale et al., 2006). Access to health care services varies across Europe and the complex regulations that govern access to health services may have led to confusion and prejudice (discrimination), making understanding and implementation of policies difficult for both health care providers and patients (Fakoya et al., 2008; Shiripinda \& Eerdewijk, 2008). Uninsured and undocumented migrants are often reluctant to be tested for HIV because of fear of access to health services if they test positive. Media attention linking HIV with migration, together with changes in migration policies throughout Europe, may also fuel the sense of social exclusion felt by many SSA migrants (Bernard, 2007; Fakoya et al., 2008).

In Belgium, about 853 sub-Saharan Africans were diagnosed HIV positive between 2011 and 2013. HIV in this group is contracted predominantly through heterosexual contact. Sub-Saharan African migrant women make up about one-third of the 14,719 HIV patients in medical care in the country (Sasse et al., 2015). Perceptions of stigma and discrimination in health care settings are a challenge to public health that need to be addressed. This study aimed to investigate stigma and discrimination among migrant sub-Saharan African women in health care settings in Belgium and their effect on the health-seeking behaviour of people living with HIV.

\section{Methods}

This qualitative study used semi-structured, in-depth interviews and observations. Hospital records were also used to complement the data. 


\section{Study sites and sampling}

Three settings were chosen for selection of the study participants: 1) an AIDS Reference Centre; 2) support group sites and 3) HIV workshop venues. The researcher gained entry to these settings through the authorization of the co-ordinators of one the AIDS Reference Centres of the university teaching hospital in Brussels, an HIV support group in Brussels and an HIV support group based at the Institute of Tropical Medicine, Antwerp.

Patients were recruited through purposive sampling and snowball techniques. Patients were eligible for inclusion if they were SSA migrant women, more than 18 years old, had been diagnosed HIV positive more than 3 months previously, were English or French speaking and were receiving health care in Belgium. Recruitment was done in two phases:

(1) Treating experts at a university teaching hospital in Brussels purposively selected patients from their consultation list and informed them about the objectives of the study during consultations. Then they invited these patients to participate and later informed the researcher whether the patient had decided to participate or not. Where a patient refused to participate, the treating professionals communicated her reasons to the researcher, who took notes on the reasons for not participating.

(2) Self-identified HIV patients receiving treatment and care at any of the nine AIDS Reference Centres in Belgium were sampled through snowball techniques during HIV workshops and seminars in Belgium. During coffee breaks, the first author (AEA) approached some of the women and introduced them to the study. Those interested agreed to participate and referred the researcher to other women whom they believed would participate in the study.

\section{Data collection}

One hundred and sixteen women were invited to participate in the study. The participants chose the venue for the in-depth interviews. In addition to interviews, informal or corridor talks with patients or members of an HIV team in response to specific events were added to enrich the data. Questions were asked about life with HIV generally and in-depth questions about stigma experiences in health care settings. These included hospitals, pharmacies and dental clinics visited by participants. Sample interview questions included:

1. How do you perceive your relationship with your HIV treating professionals?

2. Have you ever felt or experienced that you were not properly treated or obtained sub-standard care because you are HIV positive when attending any health care service?

3. What was your reaction in relation to the perceived negative attitude or behaviour of the health care provider?

Probing questions were asked to elicit the information and identifying factors that could contribute to HIV-related stigma and discrimination in health care settings were focused on. All but two interviews were digitally recorded with prior permission from the patient at the start of each interview. 


\section{Observations}

Data was also collected by observations during patients' consultations with treating physicians and attendances at support group meetings. Patients were also observed from when they arrived in the waiting room until they were ushered in by one of the HIV care givers. Observation has been found to add richness and depth to data by describing what was seen and heard (Mays \& Pope, 1995; Pettigrew, 2000). The treating physician asked the patient if the researcher could be present during the consultation. The researcher could only be present with the express permission of the patient. Notes were taken as to what was observed and heard during patientdoctor interaction. For example, observations during basic physical examinations, like taking the patient's blood pressure and measuring her weight, whether she was proactive in asking for HIV information and her concerns, were noted. The main researcher attended support group meetings at the invitation of some participants with whom a rapport had been created. During these meetings, notes were also taken as to what was observed and heard.

\section{Hospital records}

Basic data on patients' demographic details such as age of patient, year of HIV diagnosis, length of stay in Belgium and country of origin were obtained from hospital records, especially for patients who were invited but refused to be interviewed.

\section{Data analysis}

Preliminary manual analysis was inherent for interviews and observational data, which were analysed using thematic analysis (Miles \& Huberman, 1994; Minichiello, 2006) with the help of NVivo 8 for data organization and retrieval. Data analysis was done concurrently with data collection. Audio-recordings were transcribed and the transcripts read and codes generated by two researchers (AEA and RD) focusing on the main topics. For this paper, the analysis focused on transcripts of recorded interviews and notes related to participants' experiences of stigma and discrimination in health care settings. Expressions, reluctance or readiness to answer questions and frustrations on certain issues were interpreted and incorporated into the analysis. Themes were identified in the process of reading through the transcripts and the field notes. A code book was formed from themes that emerged. For example, within the category of 'stigma and discrimination', common issues were coded, such as 'rejection and abandonment by others'; 'people will run away from you'; 'name calling'; 'selfdistancing'; 'being treated after every other patient'; and 'not wanting to be seen at the clinic'. In addition memos that contained the thoughts about selected segments were written. Codes and memos formed the basis of thematic analysis, and through this process linkages and similarities were established. On the basis of the data collected, key issues were identified and modified in order to generate themes that would help describe the experiences. Finally, all concepts were grounded in the data in order to offer an understanding of the study aims. Results from the analysis and quotations to illustrate themes were reviewed by the members of the research group. 


\section{Ethical statements}

Signed informed consent was obtained from the patients after the objectives of the study were explained to them. The approved informed consent form made provision for participants to write names, contact addresses and signatures if they accepted participation. Participants could opt not to sign or give contact addresses. Patients' anonymity was assured and they could withdraw from the study at any time. Refusal to participate had no influence whatsoever on the standard of care that the patients were receiving. Interviews were conducted at a place of the participant's choice. The study was approved by the Ethics Committee (EC) of the Universitair Ziekenhuis Brussel, Belgium (approval number B.U.N. 143201215911) and the Institutional Review Board (IRB) of the Institute of Tropical Medicine, Antwerp, Belgium (approval number IRB/ $\mathrm{AB} / \mathrm{ac} / 141)$.

\section{Results}

\section{Participant characteristics}

Of the 116 patients invited to participate in the study 44 agreed to be interviewed and/or observed. One participant permitted observation in the consultation room to take place but systematically avoided all attempts by the researcher (AEA) to be interviewed. Participants were diverse in their socio-demographic characteristics and originated from fifteen countries in sub-Saharan Africa. Table 1 shows the age distribution of the 116 initial study participants. The youngest interviewee was 20 years old and the oldest was 67 years old.

Table 2 shows the demographic characteristics of the 44 interviewed women. Thirtyfive of those interviewed were mothers and nine had no child. The predominant mode of HIV transmission was heterosexual. One work-related, one perinatal and four unknown mode of transmission were reported. Apart from one mother-to-child transmission (MTCT), no participant reported having knowledge of transmission to an intimate partner or any other person. Thirty-five participants had intimate partners who were husbands, cohabiting or casual partners. Nine were single either by choice, death or abandonment by their partners.

Table 1. Demographic details of invited participants

\begin{tabular}{lr}
\hline Participant characteristics & $n$ \\
\hline Countries of origin & 15 \\
Interview status & 116 \\
$\quad$ Invited to participate & 72 \\
$\quad$ Refused to be interviewed & 44 \\
$\quad$ Interviewed & \\
Age (years) & 13 \\
$20-29$ & 26 \\
$30-39$ & 42 \\
$40-49$ & 35 \\
$50+$ & \\
\hline
\end{tabular}


Table 2. Demographic details of participants who agreed to be interviewed/observed $(N=44)$

\begin{tabular}{|c|c|c|}
\hline Characteristic & Variable & $n$ \\
\hline \multirow[t]{4}{*}{ Age (years) } & $20-29$ & 5 \\
\hline & $30-39$ & 11 \\
\hline & $40-49$ & 15 \\
\hline & $50+$ & 13 \\
\hline \multirow[t]{2}{*}{ Children } & One or more children & 35 \\
\hline & No children & \\
\hline \multirow[t]{3}{*}{ Reproductive intentions } & Pregnancy diagnosed & 14 \\
\hline & Desires pregnancy & 6 \\
\hline & Does not want to have a child & 1 \\
\hline \multirow[t]{2}{*}{ Relationship status } & Has intimate partner & 35 \\
\hline & Single without partner & 9 \\
\hline \multirow[t]{5}{*}{ Reported mode of HIV transmission } & Heterosexual & 38 \\
\hline & Homosexual & 0 \\
\hline & Health service-related & 1 \\
\hline & Perinatal & 1 \\
\hline & Unknown & 4 \\
\hline \multirow[t]{6}{*}{ Education level } & University & 12 \\
\hline & High school & 9 \\
\hline & Secondary school & 17 \\
\hline & Primary school & 1 \\
\hline & No formal schooling & 1 \\
\hline & Unknown & 4 \\
\hline \multirow[t]{2}{*}{ When learnt of HIV status } & Before leaving Africa & 9 \\
\hline & In Belgium & 35 \\
\hline \multirow[t]{4}{*}{ Employment status } & Employed & 23 \\
\hline & Retired & 4 \\
\hline & Job seeking & 13 \\
\hline & On disability benefits & 4 \\
\hline \multirow[t]{3}{*}{ Intimate partner's HIV status } & Positive & 12 \\
\hline & Negative & 21 \\
\hline & Unknown/no intimate partner & 11 \\
\hline
\end{tabular}

Many participants indicated that they received good quality health care, support and empathy from their treating HIV experts. Additionally, the main researcher (AEA) observed that the participants did not show fear of discrimination during consultations with treating physicians. The researcher also observed the proactive attitudes of the participants to engage in conversation with doctors, who did not show any sign of impatience or negative attitudes. However, several participants indicated feelings and experiences of stigma and discrimination among non-HIV health care providers in health care settings. The themes that emerged as to the causes of stigma and discrimination were: community linkage of HIV to immoral behaviour, fear of contamination and lack of proper knowledge and awareness on HIV transmission. Delayed care, excessive precautions, blame, humiliation and denial of care were 
prominent among the forms of stigma and discrimination. Participants indicated emotional stress, inconsistent health care-seeking behaviour, non-disclosure to non-HIV treating personnel, low self-esteem, urge for alternative medicine and anger as consequences of stigma and discrimination.

\section{Causes of stigma and discrimination}

Linkage of HIV to immoral behavior. Several participants indicated that, as migrants, they are susceptible to public or community stigma. HIV is perceived as a 'foreign disease' and participants felt they were blamed for its spread. Many said that people believe that African men and women have many sexual partners. For instance, a participant explained that a health care provider took her for a distributor of HIV from the way the health care provider spoke to her:

A nurse spoke to me very badly the day I was given my diagnosis. The nurse said 'you have AIDS. You are going to give it to everyone. And, how did you contract it [AIDS]?' I was in such a shock that I could not respond. The nurse continued: 'you contracted it [AIDS] because you slept with everyone'. (Participant 8, age 39)

Fear of contamination. All HIV-positive women described positive and negative interactions with health care professionals. Most of the participants from the AIDS Reference Centre (ARC) described it as the only place where they 'felt comfortable and safe to talk about the HIV disease without fear'. A majority of the participants said the doctors and nurses at the ARC were 'like family' and strongly attributed their resilience to HIV to the support and empathy they obtained from health care professionals in the ARC. However, most women reported that they had a strong belief that the attitudes and behaviours of non-HIV health care providers towards them revealed fear of contracting HIV through the service. One participant described this experience as follows:

I always ask the providers to be careful because I am HIV positive, especially as I don't know how I contracted the disease. I don't want any other person to contract this disease through me. So when I tell the service provider that I am HIV positive, he/she starts looking at you differently. One nurse told me that I could not be operated upon before the others because of my HIV-positive status. I was operated late in the day for fear of contaminating the others. When you hear words like this from a health care worker in a hospital, you don't only feel victimized but also discredited. (Participant 40, age 52)

Lack of proper knowledge and awareness of HIV transmission. Most participants expressed concern about the lack of proper knowledge of HIV transmission, prevention and management of patients by non-HIV care providers and members of the general society that stigmatizes and discriminates against HIV patients.

I usually get my medications from one pharmacy in my neighbourhood but I happened to run short of my medications during the weekend when my pharmacist was absent. I decided to go to another one to get my medications. I was shocked and ashamed when I asked for the medications and saw the pharmacist visibly trembling [demonstrating] in 
front of a large crowd waiting to be served. The attitude and behaviour he manifested, clearly indicated to people that I am sick - that I have HIV. (Participant 10, age 45)

\section{Forms of stigma and discrimination}

The most common forms of stigma and discrimination reported by participants included delayed or denied care, excessive precautions, blame and humiliation and unlawful disclosure.

Delayed or denial of care. There were reported cases of delayed or denial of care which, in the opinions of the participants, constituted stigma and discrimination. For example, three women stated a strong desire to become pregnant but they were denied fertility treatment, as one indicated:

When I expressed my desire to have a child, my gynaecologist sent me to the psychologist. I did not understand the reason because I was not depressed and knew exactly what I was asking for. I know that in Belgium women with HIV get pregnant and have children. I would have been less worried if the doctor had given me some reasons why I could not have a child. (Participant 20, age 35)

Participants also indicated delayed care because of their HIV-positive status even in situations where they needed urgent treatment and care. One woman said:

I was nine months pregnant and felt my baby was about to come. I went to the maternity unit with my husband and I was sent back home despite the fact that it was my first pregnancy and I was in much pain. Without examining me the nurses at the maternity unit asked my husband to take me back home and come back after two or three days. We went back home and immediately my waters broke and I started pushing very hard. My husband had no time to call for the ambulance. He drove me back to the hospital and I was rushed to the delivery room. I had my baby about ten minutes after I arrived. I still have pains in my lower back and I believe they originated from the unattended labour. (Participant 41, age 28)

Excessive precautions. Many participants acknowledged that non-HIV care professionals take unnecessary precautions that they perceived as discriminatory, though only a few could recall specific incidences. A participant vividly described the fact that she was always consulted last even if she was the first on the consultation list as a precautionary measure. She recalled:

Whenever I went to the hospital for non-routine HIV consultations, I was always the last to leave the waiting room. One day I was very frustrated and had to ask the doctor why the times of my appointments were never respected. He told me that it was because I am HIV positive. I felt very, very sad hearing that from someone I thought was knowledgeable about HIV. (Participant 18, age 57)

Blame and humiliation. Participants described specific attitudes and behaviours of health care professionals they believed to be stigmatizing. A participant reported her experience with a dentist as hurtful, discouraging and humiliating because the dentist 
blamed her for not personally telling her that she was HIV positive, despite the fact that the dentist had access to her electronic medical file that could be consulted before each consultation. One such negative experience was reported by a participant in these words:

Apart from my aching tooth, I had no urgent health concerns when I visited the dentist. She asked me what the problem was and I told her that my tooth ached. I waited while she consulted my electronic medical file. I was surprised and taken aback when she started shouting that I did not tell her that I am HIV positive. I told her that since it was clearly stated in my medical file which she has access to, I found it unnecessary to tell her that. I left the dentist office with the opinion that I did not get the care I was supposed to have because I was still in pain days after. (Participant 9, age 57)

\section{Unlawful disclosure}

Most participants complained about the label connoting their HIV status on the forms transiting from one service to another and felt stigmatized and discriminated that their HIV-positive status was disclosed to health care workers without their consent. One said:

I don't really think of ... but one thing I find that is not right when you have to make an appointment for a health issue is the fact that it is written on your form that you are HIV positive, which is not the case with diabetic, hypertensive or cancer patients. I find it unjust and discriminatory to have HIV written on a paper that will move from one service to another. (Participant 40, age 52)

Another woman reported:

A woman [the wife of my husband's friend] noticed that I was not breast-feeding my baby. She asked me why and I told her that I did not have enough breast milk. She was not satisfied with my response. She later informed me that she had called the maternity unit where I had my baby to inquire about me and was told that I have HIV. My husband and I were very angry and had contemplated taking legal action against the clinic for unlawful disclosure. We did not pursue with legal action because we did not want more people to know my status. (Participant 41, age 28)

\section{Consequences of stigma and discrimination}

Participants indicated refusal to disclose HIV status when seeking care, low self-esteem accompanied by emotional stress and depression, avoidance or delay seeking health care as the main consequences of stigma and discrimination.

Non-disclosure to non-HIV-treating personnel. Many participants reported that they did not disclose their HIV-positive status based on previous experiences when seeking care (for example dental care) because they felt that health care providers feared becoming infected with HIV. A participant indicated that:

I experience stigma and discrimination almost every day that I go to the hospital. This is the most serious issue that I have ever witnessed. Several times ... starting with my hospitalization [participant was hospitalized at the time of the interview]. When I got to the emergency unit, I informed them that I am HIV positive and told them what 
medications I take. I was sent to a mouth specialist, who refused to touch me and told me that he did not speak French. It was the same doctor who had earlier prescribed antibiotics without trying to find out more about my condition and it was the same doctor who had, on a previous occasion, asked that I be wheeled out of his office to the emergency unit. This is a concrete example. (Participant 22, age 55)

Notwithstanding, a few perceived that disclosure to non-HIV treatment professionals was important for prevention. One said:

When I go to the hospital, I do understand that the preventive measures taken are against the illness, not against my person. I inform them that I am HIV positive to prevent myself from contracting other viruses like hepatitis $\mathrm{C}$ or transmitting HIV to another person. When they wear three gloves before touching me, I understand their fear. (Participant 17, age 49)

Low self-esteem, emotional stress and depression. Several participants reported that they felt very low and were often deeply sad because of the way they were treated by the health care providers.

I talk with nurses and I think many people in my situation do the same. I did not look for AIDS [hand clapping] but when the nurses address you, you feel them pointing fingers at you, as if you were a street woman. It is really difficult. I did not look for AIDS [crying] ..., I did not look for AIDS [crying] ... (Participant 3, age 50)

Another participant who worked in a hospital explained how she felt when her colleagues talked about people living with HIV:

I am health care worker. It is heart-breaking and you feel very little when you listen to your colleagues criticize people who are sick or died of the illness [AIDS]. To these colleagues, it is a sin to have HIV. When you work in health care settings, you see and hear how people perceive HIV disease and people living with HIV. HIV remains a taboo not only among African communities but also in clinical settings. (Participant 39, age 53)

Avoidance of, or delay in, seeking health care. Participants indicated that they avoided going to a general practitioner (GP) or pharmacy in their neighbourhoods. In a few cases, participants reported changing clinics or GPs because of perceived maltreatment, as one participant commented:

There is a pharmacy close to where I live but I avoid going there to buy my medications because I don't want to be identified as having HIV. I prefer to buy from another pharmacy far from where I live. (Participant 3, age 50)

\section{Discussion}

This study aimed to understand the causes, forms and consequences of HIV-related stigma and discrimination against sub-Saharan African migrant women in health care settings (hospitals, pharmacies and dental clinics) in Belgium. Three important findings warrant consideration. Firstly, the root of stigma and discrimination in health care settings in Belgium emanates from pre-existing social attitudes, perceptions and 
knowledge about migrants and HIV, as well as institutional policies for handling information that make HIV-positive patients conspicuous. Secondly, the perceived or experienced stigma and discrimination varied in form. Thirdly, refusal to disclose HIV status, delay or avoidance in seeking health care, emotional stress and low self-esteem emerged as consequences of stigma and discrimination. However, most participants described their relationship with HIV-treating professionals as non-stigmatizing and non-discriminatory. According to most participants, the support and empathy of HIV physicians and nurses had greatly contributed to their ability to lead a normal life with HIV infection. This finding confirms previous studies in Africa (Okoror et al., 2014), where HIV patients indicated not being stigmatized or discriminated against by HIV providers when seeking care. However, a study in London, UK, revealed that almost half of the study participants reported having experienced stigma involving health care providers like dentists and primary care practitioners (Elford et al., 2008).

A limitation of the study is that purposive and snowball sampling was used, which could be prone to research bias. The primary recruitment source was HIV experts who provide HIV treatment and have created a rapport with the participants. The recruitment process and study topic might have affected some patients' willingness to be interviewed. It is not possible to defend the representativeness of the sample, making logical generalization difficult. However, the techniques used were cheap and simple, and allowed the researchers to reach a population that was difficult to sample using other sampling methods. Another limitation is that the study, like most qualitative studies, focused on the perceptions of study participants in order to draw its conclusions. The perceptions of these women do not prove that discrimination exists and observational studies might be needed to be sure about the extent of discrimination involving a bigger range of health care providers in different settings. However, the consistent reporting of perceived discrimination indicates that the interaction between these patients and their care-givers does pose problems.

Despite these limitations, the understanding of stigma and or discrimination in health care settings has been enriched in a resource-rich setting. This is the first qualitative study of the stigmatization and discrimination perceived by SSA migrant women in health care settings in the context of Belgium. Furthermore, the study adds to the growing body of evidence that a particularly vulnerable population like migrant women in Belgium may not feel comfortable testing, accessing health services or discussing their social and behavioural risks for HIV with providers where their identity is known. The findings also confirm the persistence of stigma and, consequently, discrimination in health care settings against SSA migrant women with HIV. The narratives of the participants were corroborated and validated by the narratives of the HIV care providers. Another strength of the study is that interviews were conducted by the first author, who had an in-depth understanding of, and similar cultural background to the participants.

For this research, measures that were taken to enhance reliability included the audio-recording of interviews to present reliable evidence and avoid bias that might occur if the researcher tried to remember the conversation or if participants changed their answer in order to please the researcher. The findings reflect the lived experiences as reported by SSA migrant women with HIV and the evidence is supported by pertinent quotations extracted from the women's narratives. Furthermore, the use of 
multi-methods (interviews, observation) to explore and corroborate the findings increased the validity of the data, consistent with previous literature (Norman et al., 2002; Rolfe, 2006; Noble \& Smith, 2015). To enhance the validity of this qualitative research, different methods of data collection were used: interviews, observations and document analysis. These data-gathering techniques allowed information from one source (interview) to be cross-checked and compared with at least one other source (notes, documents). Notes on observations were compared with interview findings. In addition, a combination of interviews and observations during consultations contributed to the richness of data. Observation was used to verify or corroborate the patient-HIV provider relationship and empathy discussed by patients during interviews. The main researcher did not observe any stigmatizing or discriminatory attitude or behaviour towards patients waiting to be consulted or during consultations. Patients' purported good relationship and interaction with their HIV care providers was confirmed during observations. The patients were ushered in with greetings, and while in the consultation room the HIV care provider generally empathized with the patients by first asking about their well-being before reviewing their medical history. However, non-HIV care providers were not included in the study.

Stigma has changed from a more discernible type to a concealed type as few participants reported actual and overt stigmatizing experiences. The concealed forms of stigma perceived through delayed or denial of care, excessive precaution-taking, blame and humiliation and unlawful disclosure can severely impact HIV-positive people, and especially migrant women's psychological well-being. Perceived and actual stigma was reported by women as having a profound impact their lives, making control of information about their situation and how to access health services serious concerns. These subtle forms of stigma are becoming more and more difficult to discern, especially by many patients who are more concerned with not being recognized by acquaintances than noticing subtleties. Furthermore, it was found that, with the exception of a very few, most participants could not indicate whether the feelings of stigma and experienced discrimination were based on their origins as migrants or of being HIV positive. Similar results have been reported in other studies (Thomas et al., 2010; Obermeyer et al., 2011; Moyer et al., 2013).

Fear of stigma and being discriminated against has continued to be a companion of the HIV pandemic since its outbreak more than 30 years ago, despite significant efforts at individual, community and institutional levels (Holzemer \& Uys, 2004; Pulerwitz et al., 2010; Aggleton et al., 2011). Generally, participants acknowledged that the magnitude of stigma and/or discrimination has greatly decreased compared with previous years. As in previous studies (Surlis \& Hyde, 2001; Letamo, 2005; Reis et al., 2005; Mahendra et al., 2007; Feyissa et al., 2012; Ekstrand et al., 2013), this study found some variation in the causes of stigma and discrimination in health care settings. It confirms that existing stigma and discrimination in society, transmission-related fear and institutional policies on HIV management, as well as lack of proper knowledge of HIV amongst health care workers not directly involved in the treatment of SSA migrant women with HIV, drive and endorse stigma feelings and discriminatory attitudes.

This study found that migration and gender are key determinants of HIV-related stigma in SSA migrant women, as found in previous research (Manfredi et al., 2001; Fakoya et al., 2008; Marsicano et al., 2014). Linkage of HIV to migration and immoral 
behaviour dates back to the early years of the HIV pandemic (Del et al., 2011; Weine \& Kashuba, 2012). For example, black Africans in London were found to be more worried about future discrimination if they tested positive, as within this community HIV transmission was perceived to be associated with promiscuity and inappropriate sexual behaviour (Erwin \& Peters, 1999). Participants indicated that, as migrants, they were susceptible to public or community stigma, especially as HIV was considered an African disease in most developed countries (Clumeck et al., 1984; Harrison-Chirimuuta \& Chirimuuta, 1997). HIV was perceived as a 'foreign disease' and participants felt that, being African and women, they were blamed for the spread of the disease, even by those who were mandated to treat and care for sick people. In the present study, women from sub-Saharan Africa with HIV believed that they were exposed to a 'triple stigma' in health care settings: that is, being Africans, they were women with immoral behaviours infected with HIV, a highly stigmatized disease. The intertwining of HIV-related stigma with migration, gender and sexism is probably why stigma and discrimination against SSA migrant women persist.

This study also supports the notion that 'labelling' can itself be stigmatizing. Participants perceived the indicator 'HIV' on their hospital appointment forms transiting from one service to another as discriminatory, as such an indicator is not used for other illnesses such as cancer and diabetes. For several participants, mentioning their HIVpositive status amounted to unauthorized disclosure by the health care institution. Health care settings are supposed to provide treatment and care, regardless of the type of disease suffered, and many participants felt that health care settings should be places where discrimination should not take place due to a patient's HIV status. Patients expect empathy from their health care workers, but this was not the perception of the study participants when they requested certain health care services. However, this study found that HIV experts mitigate the perceptions of stigma and discrimination in health care settings by creating a durable physician-patient rapport that helps to restore self-esteem, and a willingness to continue improving their quality of life with HIV. This highlights the benefits of interpersonal relationships between HIV patients and HIV health care providers.

HIV-related stigma and discrimination in health care settings have consequences. The HIV-infected SSA migrant women in this study reported avoiding or delaying seeking health care because they believed and perceived stigma and discrimination in dental services, pharmacies and other non-HIV services. Discrimination in health care settings hampers HIV treatment and care efforts, as demonstrated in previous studies in France (Kippax et al., 2007; Peretti-Watel et al., 2007; Marsicano et al., 2014) and the UK (Elford et al., 2008).

The stigma associated with HIV/AIDS is similar to that around Ebola, as experienced recently in the three West African states of Liberia, Sierra Leone and Guinea, and in the USA, where people infected with the Ebola Virus experienced stigmatizing attitudes and behaviours, including rejection, blame and fear of contagion among families, friends and health care providers. Neither disease has a cure, but they differ in that the most common mode of transmission of HIV is through sexual contact, with an emphasis on personal responsibility. If the fear of HIV is so evident among caregivers, then the fear of Ebola is probably higher, given that mortality due to Ebola occurs within a shorter time period than HIV. Ebola survivors, like HIV patients living healthy lives, do not experience stigma alleviation. 
HIV among migrant women, especially those from sub-Saharan Africa, remains a public health concern and thus it is vital that this group of women is targeted when taking measures to increase HIV/AIDS awareness and prevention. The study participants came from a region of the world with a generalized HIV pandemic, where stigmatization is common and where the culture is hard on 'deviant' members of the community. Other studies have found that social and cultural groups like migrant women from resource-limited settings with a high HIV prevalence may be disproportionately affected by being HIV positive because often these women lack the cultural understanding within the community and the health care system. More sub-Saharan African migrant women than women from other regions are HIV positive. Women are biologically and socio-culturally more vulnerable to HIV.

This study raises the possibility that SSA migrant women and other patients living with HIV may not fully utilize health care services because of perceived or experienced discrimination against them. The fact that HIV patients are still stigmatized and discriminated against today, as has been the case for 30 years, suggests that there is dire need to strengthen the information, education and communication components of HIV prevention efforts. Stigma and discrimination encourage and sustain nondisclosure and risky sexual behaviour, increasing transmission of HIV. Most study participants who had experienced or perceived stigma and discrimination at some point refrain from disclosing their HIV-positive status when they visit, for example, dentists or other medical services. The majority of the study participants were in the highly productive and reproductive age group, and HIV and opportunistic infections that would have been prevented by disclosure are very expensive to treat and contain. Presenting late with HIV may take a toll on an already over-burdened health system.

The association of HIV with immoral behaviour, lack of proper knowledge and awareness of HIV transmission and fear of contamination propagate stigma and discrimination towards people with HIV. This endangers people living with HIV, preventing early testing, treatment adherence, retention in care and preventive measures, increases the cost to the individual and public health funds. It is necessary to involve individuals, health care providers and health care policymakers in addressing stigmareduction interventions using a more extensive mixed-method research. The experiences of HIV-treating professionals should be exploited in order to export their experiences to other non-HIV health care providers. It is important to work to ensure that people with HIV/AIDS are not denied the opportunity to participate fully in all aspects of society because of stereotypes, prejudice or misinformation about HIV/AIDS, and to ensure that HIV status is taken into account only when justified by a genuine medical necessity. Specialized education and training programmes on stigma reduction for health care providers need to be introduced.

\section{Acknowledgments}

The authors would like to thank all the sub-Saharan African migrant women who agreed to participate in the study. They are also grateful to the HIV care team at the AIDS Reference Centre, Universitair Ziekenhuis Brussel, Brussels, for their assistance in the recruitment process, and thank the co-ordinators of the support groups for people 
living with HIV/AIDS who obtained permission from group members to allow the first author to be present during their meetings.

\section{References}

Adhikari, B., Kaehler, N., Chapman, R. S., Raut, S. \& Roche, P. (2014) Factors affecting perceived stigma in leprosy affected persons in western Nepal. PLoS Neglected Tropical Diseases 8(6), e2940.

Aggleton, P., Yankah, E. \& Crewe, M. (2011) Education and HIV/AIDS-30 years on. AIDS Education and Prevention 23(6), 495-507.

Alemu, T., Biadgilign, S., Deribe, K. \& Escudero, H. R. (2013) Experience of stigma and discrimination and the implications for healthcare seeking behavior among people living with HIV/AIDS in resource-limited setting. SAHARA Journal 10(1), 1-7.

Barrett, H. R. \& Mulugeta, B. (2010) Human Immunodeficiency Virus (HIV) and migrant 'risk environments': the case of the Ethiopian and Eritrean immigrant community in the West Midlands of the UK. Psychology, Health \& Medicine 15(3), 357-369.

Beldie, A., den Boer, J. A., Brain, C., Constant, E., Figueira, M. L., Filipcic, I. et al. (2012) Fighting stigma of mental illness in midsize European countries. Social Psychiatry and Psychiatric Epidemiology 47 (Supplement 1), 1-38.

Bernard, E. J. (2007) UK Report Highlights Role of Media and African Communities to Combat HIV-Related Stigma. The African HIV Policy Network (AHPN) and Panos, London.

Bertozzi, S. M., Laga, M., Bautista-Arredondo, S. \& Coutinho, A. (2006) Making HIV prevention programmes work. The Lancet 372(9641), 831-844.

Browne, J. L., Ventura, A., Mosely, K. \& Speight, J. (2013) 'I call it the blame and shame disease': a qualitative study about perceptions of social stigma surrounding type 2 diabetes. BMJ Open 3(11), $1-10$.

Canadian HIVIAIDS Legal Network (2014) Criminal Law and HIV Non-Disclosure in Canada. URL: www.aidslaw.ca/criminallaw (accessed 24th April 2015).

Chalmers, J. (2002) The criminalisation of HIV transmission. Journal of Medical Ethics 28(3), $160-163$.

Clumeck, N., Sonnet, J., Taelman, H., Cran, S. \& Henrivaux, P. (1984) Acquired immune deficiency syndrome in Belgium and its relation to Central Africa. Annals of the New York Acadamy of Sciences 437, 264-269.

Conn, C. (2013) Young African women must have empowering and receptive social environments for HIV prevention. AIDS Care 25(3), 273-280.

Davtyan, M., Brown, B. \& Folayan, M. O. (2014) Addressing Ebola-related stigma: lessons learned from HIV/AIDS. Global Health Action 7, 1-4.

De Cock, K. M., Jaffe, H. W. \& Curran, J. W. (2011) Reflections on 30 years of AIDS. Emerging Infectious Disease 17(6), 1044-1048.

Del, A. J., Likatavicius, G., Perez-Cachafeiro, S., Hernando, V., Gonzalez, C., Jarrin, I. et al. (2011) The epidemiology of HIV and AIDS reports in migrants in the 27 European Union countries, Norway and Iceland: 1999-2006. European Journal of Public Health 21(5), 620-626.

DeMarco, R. F., Kendricks, M., Dolmo, Y., Looby, S. E. \& Rinne, K. (2009) The effect of prevention messages and self-efficacy skill building with inner-city women at risk for HIV infection. Journal of the Association of Nurses in AIDS Care 20(4), 283-292.

ECDC (2012) Responses to HIV and Migration in Western Industrialized Countries: Current Challenges, Promising Practices, Future Directions. European Centre for Disease Control, Stockholm. URL: http://www.ecdc.europa.eu/en/publications/publications/hiv-migration-meeting-report.pdf (accessed 11th February 2013). 
Ekstrand, M. L., Ramakrishna, J., Bharat, S. \& Heylen, E. (2013) Prevalence and drivers of HIV stigma among health providers in urban India: implications for interventions. Journal of the International AIDS Society 16(3) (Supplement 2), 18717.

Elford, J., Ibrahim, F., Bukutu, C. \& Anderson, J. (2008) HIV-related discrimination reported by people living with HIV in London, UK. AIDS Behavior 12(2), 255-264.

Erwin, J. \& Peters, B. (1999) Treatment issues for HIV+ Africans in London. Social Science \& Medicine 49(11), 1519-1528.

Fakoya, I., Reynolds, R., Caswell, G. \& Shiripinda, I. (2008) Barriers to HIV testing for migrant black Africans in Western Europe. HIV Medicine 9 (Supplement 2), 23-25.

Feyissa, G. T., Abebe, L., Girma, E. \& Woldie, M. (2012) Validation of an HIV-related stigma scale among health care providers in a resource-poor Ethiopian setting. Journal of Multidisciplinary Healthcare 5, 97-113.

Goffman, E. (1963) Stigma: Notes on the Management of Spoiled Identity. Simon \& Schuster Inc., New York.

Grossman, C. I. \& Stangl, A. L. (2013) Editorial: global action to reduce HIV stigma and discrimination. Journal of the International AIDS Society 16(3) (Supplement 2), 18881.

Hackl, K. L., Somlai, A. M., Kelly, J. A. \& Kalichman, S. C. (1997) Women living with HIV/ AIDS: the dual challenge of being a patient and caregiver. Health \& Social Work 22(1), 53-62.

Harrison-Chirimuuta, R. \& Chirimuuta, R. (1997) AIDS and Africa: a case of racisim vs science? In Bond, G. C., Krensike, J., Susser, I. \& Vincent, J. (eds) AIDS and Africa and the Carribbean. Westview Press.

Hatzenbuehler, M. L., Phelan, J. C. \& Link, B. G. (2013) Stigma as a fundamental cause of population health inequalities. American Journal of Public Health 103(5), 813-821.

Heijnders, M. \& Van Der Meij, S. (2006) The fight against stigma: an overview of stigma-reduction strategies and interventions. Psychology, Health \& Medicine 11(3), 353-363.

Holzemer, W. L. \& Uys, L. R. (2004) Managing AIDS stigma. SAHARA Journal 1(3), 165-174.

Juniarti, N. \& Evans, D. (2011) A qualitative review: the stigma of tuberculosis. Journal of Clinical Nursing 20(13-14), 1961-1970.

Kipp, A. M., Pungrassami, P., Nilmanat, K., Sengupta, S., Poole, C., Strauss, R. P. et al. (2011) Socio-demographic and AIDS-related factors associated with tuberculosis stigma in southern Thailand: a quantitative, cross-sectional study of stigma among patients with TB and healthy community members. BMC Public Health 11, 675.

Kippax, S. C., Aggleton, P., Moatti, J. P. \& Delfraissy, J. F. (2007) Living with HIV: recent research from France and the French Caribbean (VESPA study), Australia, Canada and the United Kingdom. AIDS 21 (Supplement 1), S1-S3.

Kralik, D., Koch, T. \& Telford, K. (2001) Constructions of sexuality for midlife women living with chronic illness. Journal of Advances Nursing 35(2), 180-187.

Lauderdale, D. S., Wen, M., Jacobs, E. A. \& Kandula, N. R. (2006) Immigrant perceptions of discrimination in health care: the California Health Interview Survey 2003. Medical Care 44(10), 914-920.

Letamo, G. (2005) The discriminatory attitudes of health workers against people living with HIV. PLoS Medicine 2(8), e261.

Liamputtong, P. (2013) Women, Motherhood and Living with HIVIAIDS: A Cross-Cultural Perspective. Springer, Bundoora, Australia, doi:10.1007/978-94-007-5887-2.

Lin, C., Li, L., Wan, D., Wu, Z. \& Yan, Z. (2012) Empathy and avoidance in treating patients living with HIV/AIDS (PLWHA) among service providers in China. AIDS Care 24(11), 1341-1348.

Link, B. G. \& Phelan, J. C. (2001) Conceptualizing Stigma. Annual Review of Sociology 27(1), $363-385$.

Link, B. G. \& Phelan, J. C. (2006) Stigma and its public health implications. Lancet 367(9509), $528-529$. 
Mahendra, V. S., Gilborn, L., Bharat, S., Mudoi, R., Gupta, I., George, B. et al. (2007) Understanding and measuring AIDS-related stigma in health care settings: a developing country perspective. SAHARA Journal 4(2), 616-625.

Manfredi, R., Calza, L. \& Chiodo, F. (2001) HIV disease among immigrants coming to Italy from outside of the European Union: a case-control study of epidemiological and clinical features. Epidemiology \& Infection 127(3), 527-533.

Marsicano, E., Dray-Spira, R., Lert, F., Aubriere, C., Spire, B. \& Hamelin, C. (2014) Multiple discriminations experienced by people living with HIV in France: results from the ANRSVespa2 study. AIDS Care 26 (Supplement 1), S97-S106.

Mays, N. \& Pope, C. (1995) Qualitative research: observational methods in health care settings. British Medical Journal 311(6998), 182-184.

Miles, M. J. \& Huberman, A. M. (1994) Qualitative Data Analysis: An Expanded Source Book, 2nd edition. Sage Publications, CA.

Minichiello, V. (2006) Book reviews: qualitative research methods. Australian and New Zealand Journal of Public Health 30(2), 190-196.

Moyer, E., Igonya, E. K., Both, R., Cherutich, P. \& Hardon, A. (2013) The duty to disclose in Kenyan health facilities: a qualitative investigation of HIV disclosure in everyday practice. SAHARA Journal 10 (Supplement 1), S60-S72.

Noble, H. \& Smith, J. (2015) Issues of validity and reliability in qualitative research. Evidence Based Nursing 18(2), 34-35.

Norman, I. J., Watson, R., Murrells, T., Calman, L. \& Redfern, S. (2002) The validity and reliability of methods to assess the competence to practise of pre-registration nursing and midwifery students. International Journal of Nursing Studies 39(2), 133-145.

Nyblade, L., Singh, S., Ashburn, K., Brady, L. \& Olenja, J. (2011) 'Once I begin to participate, people will run away from me': understanding stigma as a barrier to HIV vaccine research participation in Kenya. Vaccine 29(48), 8924-8928.

Obermeyer, C. M., Baijal, P. \& Pegurri, E. (2011) Facilitating HIV disclosure across diverse settings: a review. American Journal of Public Health 101(6), 1011-1023.

Okall, D. O., Ondenge, K., Nyambura, M., Otieno, F. O., Hardnett, F., Turner, K. et al. (2014) Men who have sex with men in Kisumu, Kenya: comfort in accessing health services and willingness to participate in HIV prevention studies. Journal of Homosexuality 61(12), $1712-1726$.

Okoror, T. A., Belue, R., Zungu, N., Adam, A. M. \& Airhihenbuwa, C. O. (2014) HIV positive women's perceptions of stigma in health care settings in Western Cape, South Africa. Health Care Women International 35(1), 27-49.

Parker, R. (2012) Stigma, prejudice and discrimination in global public health. Cadernos de Saúde Pública 28(1), 164-169.

Parker, R. \& Aggleton, P. (2003) HIV and AIDS-related stigma and discrimination: a conceptual framework and implications for action. Social Science \& Medicine 57(1), 13-24.

Peretti-Watel, P., Spire, B., Obadia, Y. \& Moatti, J. P. (2007) Discrimination against HIV-infected people and the spread of HIV: some evidence from France. PLoS One 2(5), e411.

Pettigrew, S. F. (2000) Ethnography and grounded theory: a happy marriage? Advances in Consumer Research 27, 256-260.

Pulerwitz, J., Michaelis, A., Weiss, E., Brown, L. \& Mahendra, V. (2010) Reducing HIV-related stigma: lessons learned from Horizons research and programs. Public Health Reports 125(2), 272-281.

Rance, J. \& Treloar, C. (2014) 'We are people too': consumer participation and the potential transformation of therapeutic relations within drug treatment. International Journal of Drug Policy, doi: S0955-3959(14)00099-1. 
Reis, C., Heisler, M., Amowitz, L. L., Moreland, R. S., Mafeni, J. O., Anyamele, C. et al. (2005) Discriminatory attitudes and practices by health workers toward patients with HIV/AIDS in Nigeria. PLoS Medicine 2(8), e246.

Rolfe, G. (2006) Validity, trustworthiness and rigour: quality and the idea of qualitative research. Journal of Advanced Nursing 53(3), 304-310.

Saleem, H. T., Surkan, P. J., Kerrigan, D. \& Kennedy, C. E. (2015) Childbearing experiences following an HIV diagnosis in Iringa, Tanzania. Qualitative Health Research, doi: 1049732315605273 .

Sartorius, N. (2009) Illnesses of the health system. Psychiatria Danubina 21(4), 444-445.

Sasse, A., Van Beckhoven, D. \& Verbrugge, R. (2015) Epidemiology of AIDS and HIV infection in Belgium. Scientific Institute of Public Health, Brussels, Belgium. URL: https://www.wiv-isp.be/ pages/en-home.aspx (accessed 25th January 2016).

Seedat, F., Hargreaves, S. \& Friedland, J. S. (2014) Engaging new migrants in infectious disease screening: a qualitative semi-structured interview study of UK migrant community healthcare leads. PLoS One 9(10), e108261.

Shefer, G., Rose, D., Nellums, L., Thornicroft, G., Henderson, C. \& Evans-Lacko, S. (2013) 'Our community is the worst': the influence of cultural beliefs on stigma, relationships with family and help-seeking in three ethnic communities in London. International Journal of Social Psychiatry 59(6), 535-544.

Shiripinda, I. \& Eerdewijk, A. H. J. M. V. (2008) Facing HIV in The Netherlands: Lived Experiences of Migrants Living with HIV. Pharos, Utrecht. URL: http://hdl.handle.net/ 2066/73172.

Sidibe, M. \& Goosby, E. P. (2013) Foreword: global action to reduce HIV stigma and discrimination. Journal of the International AIDS Society 16(3) (Supplement 2), 18893.

Simbayi, L. C., Kalichman, S., Strebel, A., Cloete, A., Henda, N. \& Mqeketo, A. (2007) Internalized stigma, discrimination, and depression among men and women living with HIV/AIDS in Cape Town, South Africa. Social Science \& Medicine 64(9), 1823-1831.

Skinner, D. \& Mfecane, S. (2004) Stigma, discrimination and the implications for people living with HIV/AIDS in South Africa. SAHARA Journal 1(3), 157-164.

Surkan, P. J., Mukherjee, J. S., Williams, D. R., Eustache, E., Louis, E., Jean-Paul, T. et al. (2010) Perceived discrimination and stigma toward children affected by HIV/AIDS and their HIV-positive caregivers in central Haiti. AIDS Care 22(7), 803-815.

Surlis, S. \& Hyde, A. (2001) HIV-positive patients' experiences of stigma during hospitalization. Journal of the Association of Nurses in AIDS Care 12(6), 68-77.

Taylor, D. C. (2013) Stigma and prejudice in the language of sickness. Epilepsy \& Behavior 27(1), 204-205.

Thomas, F., Aggleton, P. \& Anderson, J. (2010) 'Experts', 'partners' and 'fools': exploring agency in HIV treatment seeking among African migrants in London. Social Science \& Medicine 70(5), 736-743.

Thomas, S. L., Hyde, J., Karunaratne, A., Herbert, D. \& Komesaroff, P. A. (2008) Being 'fat' in today's world: a qualitative study of the lived experiences of people with obesity in Australia. Health Expectations 11(4), 321-330.

Weine, S. M. \& Kashuba, A. B. (2012) Labor migration and HIV risk: a systematic review of the literature. AIDS Behavior 16(6), 1605-1621. 